\title{
Penile Fracture and Magnetic Resonance Imaging
}

\author{
Katie S. Murray, Michael Gilbert, Lawrence R. Ricci, Narendra Khare, Joshua Broghammer
}

University of Kansas Medical Center Department of Urology (KSM, JB), Kansas City, KS, University of Missouri-Kansas City Department of Urology (NK) and Department of Radiology (MG, LRR), Kansas City, MO, USA

A thirty-three-year-old male presented to an outside emergency department with scrotal swelling and pain after intercourse. A scrotal ultrasound revealed hematoma, with no other abnormalities and the patient was discharged. He then presented to our institution where examination showed diffuse ecchymosis through the shaft of the penis, suprapubic region, and scrotum without a palpable cavernosal defect.

Magnetic resonance imaging (MRI) without contrast was obtained after the injection of 10 micrograms of intracavernosal alprostadil. The low signal tunica albuginea is easily demar-

Figure 1 - Coronal T1 image shows disruption of the low intensity inferior left tunica albuginea and associated low signal corpus cavernosal hematoma at the base of the penis.

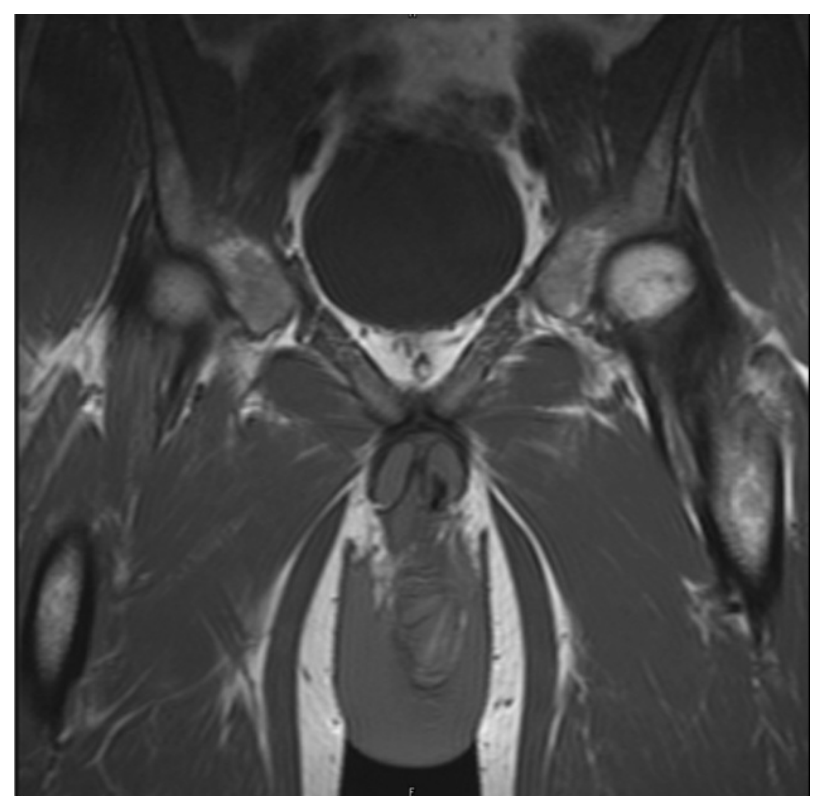

cated compared to the high T2 and intermediate $\mathrm{T} 1$ signal of the corpora cavernosum (Figures 1-3) $(1,2)$. Hematoma shows heterogeneous intermediate T1 and T2 signal (Figures 2 and 3) (1).

Penile fracture is rupture of the corpus cavernosum from blunt trauma to the erect penis $(3,4)$. Typical presentation is a pop during intercourse, immediate detumescence with edema, hematoma and penile deformity $(3,4)$. In atypical presentations, radiological studies may be useful to determine the diagnosis. MRI provides the ability to identify disruption of the corpus cavernosum due to excellent tissue contrast and

Figure 2 - The heterogeneous left scrotal hematoma and low signal left corpus cavernosum hematoma are more conspicuous on this T2 coronal image.

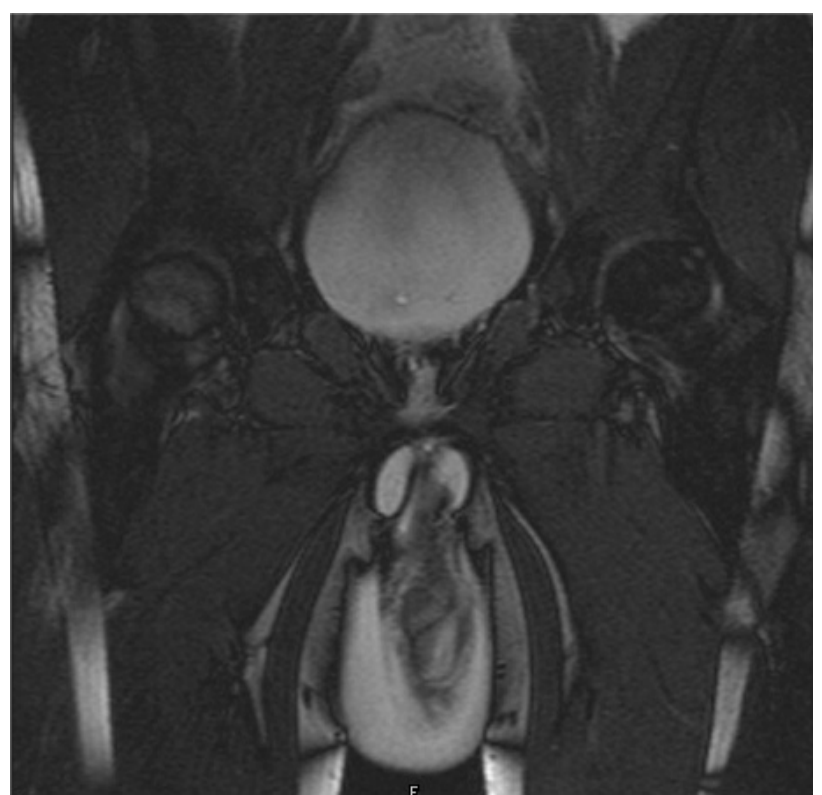


Figure 3 - Coronal T2 image shows disruption of the linear low signal left tunica albuginea at the base of the penis with associated heterogeneous hemorrhage medially.

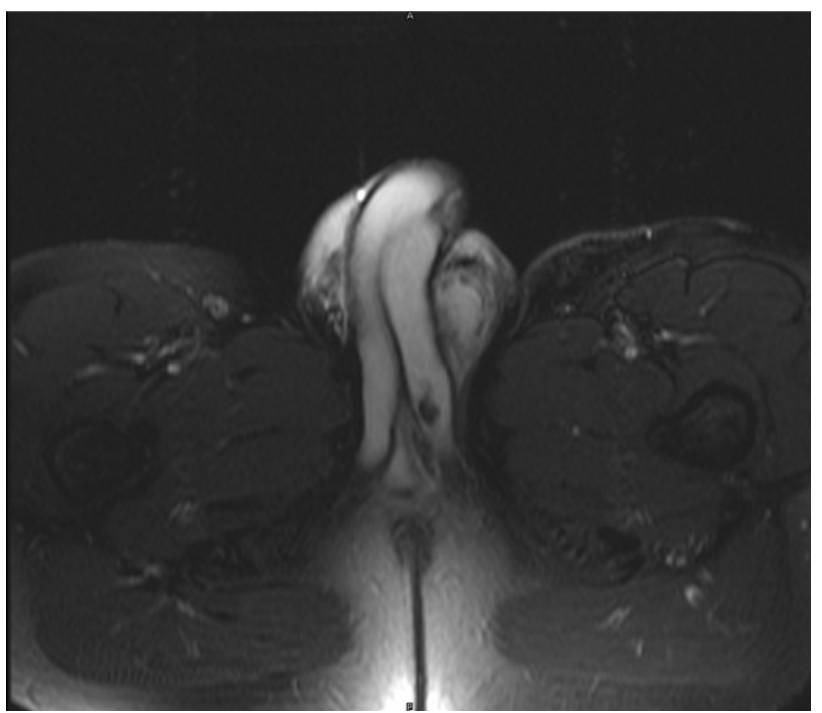

visualization of soft tissue pathological processes (5). MRI is an adjunctive tool in the evaluation of atypical presentations of suspected penile fracture (3).

\section{REFERENCES}

1. Fedel M, Venz S, Andreessen R, Sudhoff F, Loening SA: The value of magnetic resonance imaging in the diagnosis of suspected penile fracture with atypical clinical findings. J Urol. 1996; 155: 1924-7.

2. Choi MH, Kim B, Ryu JA, Lee SW, Lee KS: MR imaging of acute penile fracture. Radiographics. 2000; 20: 1397-405. Erratum in: Radiographics. 2000; 20: 1818.

3. Koifman L, Barros R, Júnior RA, Cavalcanti AG, Favorito LA: Penile fracture: diagnosis, treatment and outcomes of 150 patients. Urology. 2010; 76: 1488-92.

4. El-Assmy A, El-Tholoth HS, Abou-El-Ghar ME, Mohsen T, Ibrahiem el HI: False penile fracture: value of different diagnostic approaches and long-term outcome of conservative and surgical management. Urology. 2010; 75: 1353-6.

5. Rahmouni A, Hoznek A, Duron A, Colombel M, Chopin DK, Mathieu $D$, et al.: Magnetic resonance imaging of penile rupture: aid to diagnosis. J Urol. 1995; 153: 1927-8.

\section{Correspondence address:}

Dr. Katie Murray Department of Urology University of Kansas Medical Center 3901 Rainbow Blvd Mail Stop 3016

Kansas City, KS 66160

Fax: 913-588-6668

E-mail: kmurray3@kumc.edu 